\title{
How Business Departments Manage the Requirements Engineering Process in Information Systems Projects in Small and Medium Enterprises
}

\author{
Rüdiger Weißbach \\ University of Applied Sciences, Hamburg, Germany
}

ruediger.weissbach@haw-hamburg.de

\begin{abstract}
In literature, the Requirements Engineering [RE] process in information system projects is typically presented as a process conducted by requirement engineers or similar skilled persons on the developer's site. In this paper the author presents the preliminary results of a survey about the way how business departments are engaged in the RE process. The author conducted semistructured interviews in 25 companies, most of them Small and Medium Sized Enterprises [SMEs], with persons of different departments. The results show that the business departments often conduct the whole RE process itself or at least a part of it. The project success does not depend on who conducts the process but on how the process is done.
\end{abstract}

Keywords: Information Systems, Business Departments, Requirements Engineering, Requirements Management, Small and Medium Enterprise.

\section{Introduction}

In literature on Requirements Engineering [RE], the RE process in information system projects is typically presented as a process conducted by requirement engineers, system engineers or similar skilled persons on the developer's site. In RE literature the participation of the future users or other stakeholders is seen as more passive: They are respondents in the process of RE elicitation. These scenarios are different to the author's experience and they leave unanswered questions: How will be the RE process conducted in projects without an explicit role for a requirements engineer? Especially small and medium enterprises [SMEs] are working without an explicit requirements engineer, sometimes even without qualified IT staff.- And how will the RE process be conducted in continuous improvement and in "line management"?

To get a more differentiated view on the RE reality in SMEs the author started a research project in 2009, "Business Departments in the Process of Requirements Engineering in Information Sys-

Material published as part of this publication, either on-line or in print, is copyrighted by the Informing Science Institute. Permission to make digital or paper copy of part or all of these works for personal or classroom use is granted without fee provided that the copies are not made or distributed for profit or commercial advantage AND that copies 1) bear this notice in full and 2) give the full citation on the first page. It is permissible to abstract these works so long as credit is given. To copy in all other cases or to republish or to post on a server or to redistribute to lists requires specific permission and payment of a fee. Contact Publisher@InformingScience.org to request redistribution permission. tems Projects", in German translation "Fachabteilungen im Prozess der Anforderungsanalyse" [FaPrAa] . 
Due to the lack of research to this topic the scope of this project is a pilot study. The objective of this project is to analyze:

- in which scope,

- in which function and

- with which methodological base

business departments staff is involved in the RE process. The term "business departments" means departments, whose main mission is not the technological development of information systems. (This does not exclude "End-User Development" [EUD], see below, Related Work.) We have to regard that the members of the business departments could neither be seen stringently as internal clients in the meaning of paying or sponsoring the project nor as future users. The members of the business departments are stakeholders in the meaning of being affected of a project.

One assumption behind this research question is, that RE is an "area of expertise", not only an organizational role. Area of expertise means a set of methods, knowledge and skills that enables a person to produce results of a certain type (Fahney et al., 2007).

The remainder of this paper is structured as follows: The next chapter presents the relevance of the topic and the related work. The paper progresses with methodological information, followed by the findings, the discussion of them and proposals to further work. This paper finishes with the conclusions.

\section{Background}

\section{Relevance of the Topic}

The relevance of requirements for the success or the failure of projects is noted in literature (e.g. Engel \& Holm, 2007; Standish Group, 2001). Requirements are elicited and managed in the Requirements Engineering [RE] process. The RE process in information system projects is typically presented - for example in lecture books (e.g. Ebert, 2012; Pohl \& Rupp, 2011; Robertson \& Robertson, 2006) - as a process conducted by well-qualified requirement engineers, system analysts or similar skilled persons on the developer's site, who elicit the requirements from the users. In these models the users and the managers of the business departments are involved as stakeholders, but not as acting people in the process.

Own experience shows a different situation: Business departments define their requirements itself for business information systems and they manage contracts with external IT companies. But this had not been an established research topic (see for example the overview of RE related research in Cheng \& Atlee, 2007; Davey \& Cope, 2008) and was not seriously discussed in lecture books (e.g. Ebert, 2012; Pohl \& Rupp, 2011; Robertson \& Robertson, 2006).

This insufficient consideration in research leads to some problems:

1. The complexity of current real-world processes will not be understood. Especially the situation in SMEs will not be represented in its diversity. SMEs will typically not hire specialized staff for requirements engineering (if not ICT companies).

2. Respecting new service products as Software-as-a-Service the responsibility of business departments for information processing is expected to increase (Capgemini, 2012). Therefore the gap between research and reality might increase.

\section{Related Work}

In the last decade, the "paradigm" (Pipek \& Wulf, 2009) of "End-User Development" [EUD] was discussed in literature (Fischer 2009). According to Lieberman et al., "EUD can be defined as a 
set of methods, techniques, and tools that allow users of software systems, who are acting as nonprofessional software developers, at some point to create, modify, or extend a software artifact." (Lieberman et al., 2006, p.2).

The focus of the study differs to papers published on the topic of EUD:

- The paradigm of EUD relates on the whole process of software development, with a relevant importance of the running artifact. The origin of the FaPrAa study is the RE process.

- EUD means the participation of the "end users". Business department employees are not automatically future users. The FaPrAa study analyzes the participation of business department staff, regardless their future role as users or non-users.

The FaPrAa study analyzes in which way RE will be conducted in the organizational praxis, especially in SMEs.

\section{Methodology}

Due to the function of a pilot study, the objective of the FaPrAa study is to develop hypotheses by analyzing qualitative data. Representativeness in a mathematical understanding is not intended. The FaPrAa study uses case studies (Yin, 2009) elicited in semi-structured interviews. The epistemological base is the Grounded Theory of Glaser/Strauss.

The FaPrAa study started in the autumn of 2009 with a literature survey focused on requirements engineering literature. This survey confirms the initial glimpse, that the active role of business departments in the RE process is an overseen topic in literature.

From September 2010 to June 2011 the author conducted 25 semi-structured interviews in different companies with 29 participants. 5 interview partners could be acquired by personal contacts. To acquire the other 20 companies around 700 telephone calls have been needed. One interview (with a previously known partner) was conducted by mail, the other interviews face-to-face. All interviews had been conducted by the author.

The interviews based on a semi-structured questionnaire. They started with information about the research study. The following questions requested information about

- the position, the role and the professional education of the interviewees,

- the company and its organizational structure, especially regarding project management and IT management,

- the importance of project work in the organization,

- the relevance of "systematic RE" for the organization,

- the actors in the RE process (in project work and in line management) and their mode of collaboration,

- the complexity of the RE process (complete vs. rudimental requirements),

- the methods use in the RE process (elicitation, structuring, documentation, clearance, management),

- the evolution of and the expectations about the RE process in the company.

The first five interviews, conducted with personally known people, have been used as test for the questionnaire, which could be used without changes. The questionnaire was handed out to the interviewees. The wording of the questions was not fixed. The term "requirements engineering" for example was used in combination with the German term ("Anforderungsanalyse"). The sequence of the questions was flexible and additional questions had been put dependent on the answers of the interviewees. The order of the questions was changed respecting the course of the interview. The interviews could be characterized as "discussions between professionals". 
The face-to-face interviews took from 30 to 90 minutes and had been recorded with an audio recorder. These audio files had been transcribed by a student assistant and encoded by using MAXQDA software for qualitative data analysis. To reduce the impact of misunderstanding in the interview communication, specific RE vocabulary was only used if the interview partners showed knowledge about the RE subjects and the specific terms. The transcriptions were acknowledged by the interviewees.

Most of the participating companies are SMEs in the definition of the European Community (European Community, 2003), that means they have less than 250 employees and a turnover not higher than 50 million $€$. The companies cover diverse branches, for example consultancy, financial services, removal and storage, retail, food, mechanical engineering, information services.

Table 1gives an overview of the structure of the participating companies. Different to (European Community, 2003) the turnover is no accounted as criterion and companies with $250+$ employees are divided into two groups (private ownership vs. affiliated group). This table does not reflect the whole complexity, because some small companies are parts of larger structures.

\begin{tabular}{|c|c|c|c|c|c|c|}
\hline \multicolumn{7}{|c|}{ Table 1: Structure of participating companies } \\
\hline \multirow[t]{2}{*}{$\begin{array}{l}\text { Classification according to } \\
\text { (UN, 2008) }\end{array}$} & \multicolumn{6}{|c|}{$\begin{array}{l}\text { Numbers of employees, categorization bases on } \\
\text { (European Community, 2003) }\end{array}$} \\
\hline & $\begin{array}{c}250+, \\
\text { affiliat- } \\
\text { ed group }\end{array}$ & $\begin{array}{l}250+, \\
\text { private }\end{array}$ & $\begin{array}{l}\text { Medium } \\
(>=50)\end{array}$ & $\begin{array}{c}\text { Small } \\
(>=10)\end{array}$ & $\begin{array}{l}\text { Micro } \\
(<10)\end{array}$ & SUM \\
\hline C (Manufacturing) & 4 & & 3 & 2 & & 9 \\
\hline $\mathrm{G}$ (Wholesale and retail trade) & 1 & 3 & 1 & 1 & 1 & 7 \\
\hline $\mathrm{H}$ (Transport and storage) & & & 2 & & & 2 \\
\hline $\begin{array}{l}\mathrm{J} \text { (Information and Communi- } \\
\text { cation) }\end{array}$ & & & & 1 & & 1 \\
\hline $\begin{array}{l}\text { K (Financial insurance activi- } \\
\text { ties) }\end{array}$ & 1 & & & 1 & & 2 \\
\hline $\begin{array}{l}\text { M (Professional, scientific and } \\
\text { technical activities) }\end{array}$ & & & & 3 & & 3 \\
\hline $\begin{array}{l}\text { N (Administrative and support } \\
\text { service activities) }\end{array}$ & & & & 1 & & 1 \\
\hline SUM & 6 & 3 & 6 & 9 & 1 & 25 \\
\hline
\end{tabular}

The interview partners worked in diverse functions, in IT departments, in business departments or as management executives. The interview partners reported about successful projects as well as about failure stories.

\section{Findings}

According to the research objectives, the findings of the study are structured as follows:

- scope of partizipation

- function of partizipation

- methodological base of the partipization

\section{Scope of Participation - Actors in the Requirements Engineering Process}

In contradiction to the state of the art none of the participating companies defined a specific positions for actors in the RE process a specific RE role. In a few cases companies were introducing a 
dedicated role of a process manager or project management office (a small company in an affiliated group and a retail company with 2000 employees in private ownership).

In most projects the project managers - regardless of their department - have been responsible for the RE process. In "non-projects", line managers of the business departments as trigger of information system changes had this function. Sometimes the RE process was performed as an outsourced task by extern staff. In some cases the IT staff performed the RE - "you only can develop what you understood".

\section{Function of Participation}

\section{Scenarios in the requirements engineering process}

As a result of the analysis of the cases the following scenarios in the RE process could be observed:

\section{a. Starting the project without explicit RE}

This scenario could be observed at a small web shop startup company.

The founders of the company had a vision of a business idea, which was a copy of an US American web shop. They started to work imitating this web shop.

This approach was not successful and the company had to do rework.

b. Business departments have the best knowledge about their tasks (and conduct the RE process themselves)

In companies with skilled work, blue and white cellar workers both have experience in performing their tasks with a certain level of own responsibility. They have knowledge not only in the working process but in the improvement of this process too.

c. IT departments have enough domain knowledge to lead the RE process In some companies, the IT departments have a long tradition with low employee turnover. In these companies, the IT staff acquired domain knowledge and due to the more generalist view of the IT staff they can conduct the RE process. They have experience in identifying contradictions in requirements, forgotten requirements etc.

In some aspects - long-term employed, experienced and skilled staff, personal responsibility - the scenarios (b) and (c) are similar, but they differ in the actor who conducts the process.

d. Business departments are experts in domain knowledge, IT departments are experts in methods and technology

This model is the "classical" model in RE literature: Persons in the role of a requirements engineer, a system analyst, a developer and similar functions are qualified for the RE process and elicit the requirements from the members of the business departments. This structure needs qualifications in IT department that exceed the "technical only" skills for system and network operating. Such IT departments are not common in SMEs. The IT departments are originated typically in the technical support.

e. "IT departments" are not restricted on information technology - they are managing the process organization too

This model could be found in

- larger organizations,

- organizations with an innovative aspiration,

- organizations embedded in larger structures (members of a concern or a network [i.e. franchise partners, regional banks in a network, ...) 
- and - in general - in the financial service branch: Since decades companies in the financial service branch are ought to install an internal monitoring system to organize and to monitor processes, regardless of the company's size. Because almost all processes in the financial service branch are performed in IT systems, this duty might be a reason for the organizational competence of the IT departments.

f. Responsibility for the RE process changes between projects (IT departments) and line organization (business departments)

Especially organizations with well-defined processes and organizational structures use a threshold for defining processes by a certain value of invest or manpower. Work which will not pass this threshold will not be conducted as projects, but as "normal business". The CIP [continuous improvement process] is a core task of line managers. They are not only ought to supervise their staff but to improve the processes too. In this function they are responsible to develop own ideas and requirements.

g. Management executives (sometimes together with externals) are defining requirements in a top down approach

In certain situations top management will define not only the general aims of a project, but detailed requirements too. Possible situations will be:

- Major structural changes in an organization ("Change Management")

- Complex requirements and/or insufficient staffed organization

- Top management is involved in peer groups with similar situation (managers' club, networking groups)

\section{Methodological Base of the Partipization}

\section{Documentation of the requirements}

The modes of (non-) documentation are different. In the worst case the source code of old software is the only documentation (if the source is still available or valid). But system reengineering was not mentioned as RE method.

In project work documentation plays a more relevant role than in ongoing optimization. During a project the documentation artifacts are different. Some companies have their own document standards. In one organization (small retail company for safety products), an ISO 9001 process document was made and this artifact was used as leading document in the selection process for a standard software solution. That was the highest maturity level observed in this survey. But in most cases organizations did not use well-structured documents.

Instead of standardized well-structured documents organizations often use few unstructured documents or only "aural tradition". Some organizations use protocols of the project meetings as current project documentation. The requirements are represented by the sum of the protocols. Consistency and completeness must be worked out by the readers of the protocols. The advantage is seen in the actuality of this procedure and in the process integration of this documents: Protocols are read by every participant.

\section{Working with tools and methods}

Special software tools for RE are in the market for years but they had not been used in any of the surveyed organizations. Instead of such special tools organizations are using office software, especially word processing and spreadsheet software for the documentation of the requirements. 
Sometimes project workers use less formal methods for description. Use Case diagrams had been noted several times. In one company an experienced IT manager, who formerly worked in a major company, used SADT diagrams. The missing of methods had not be seen as a relevant problem for the RE process.

\section{Best and Worst Practices - and the Problems in Between}

The interviewees reported on successful projects and line work regardless of the general organization of the RE tasks. The mentioned success factors and problems deal on a more detailed level.

Some practices have been stated by the interviewees as important for the project success:

- continuous meetings between business and IT departments, mixed teams (regardless if in project work or in "normal production")

- written documentation of workshops and meetings

- using scenario technique

- similar experiences and ways of thinking at business and IT workers (with the mentioned risk that documentation is treated as not necessary)

The benefits of the continuous meetings are

- establishing of communities and common understanding

- the relevance of topics is changing over time

- some problems become apparent only after time

An important problem for some organizations is the difference between maintenance and project work. The definition of an effort threshold enables better possibilities for management. A typical threshold is the limit of 5 days.

Problems have been seen in the lack of understanding of the importance of data modeling and in a missing institutionalization of change requests.

Some worst practices have been seen

- in missing documentation of the knowledge (manufacturing company with ca. 300 emloyees, a special software is running for 15 years without changes on old platforms) and

- in completely different areas of knowledge between the actors in the process.

\section{Expectations - How the Process will be in Future}

The participants expect less ad hoc development and more structure in the processes in future, regardless of the diffusion of agile models. These changes to more formalization and structure need triggers. The interviewees mentioned the following triggers:

\section{- new projects}

The start of a new project had different kinds of impact for the formalization of the processes.

○ successfully proven processes could be continued constantly

- the failure of a former project triggers a more formalized process model

- former projects had been conducted successfully, but the management wanted to improve quality in general

- former projects had been conducted successfully, but a new project was estimated as more complex, so that a process change was initiated 
- co-operation with externals

The relationship between the client and the external supplier needs contracts. Detailed Specifications are an important part of these contracts. The demands of co-operating banks (BASEL II) had been another trigger for a stronger formalization.

- $\quad$ replacement of existing systems

The replacement of an existing system shows the quality of the documentation. Problems caused an awareness of RE.

- new organization

New management, growth or changes in the business models triggered the formalization of the internal processes too.

\section{Discussion}

\section{Methodological Aspects and Validity}

At first, the FaPrAa study is qualitative research with only 25 interview partners. For this reason, the results are not representative. This limitation was intended, because the mining of hypotheses was the focus of the work.

All personally conducted interviews are biased by the interviewer. In the FaPrAa study the author was the only interviewer, so that he risk of different biases was reduced. The interviewer's understanding of the problem was high, so that misunderstanding was reduced. From the other point of view, the position of the interviewer as professor for business informatics could be seen as a potential threat of the competence of the interviewees.

A strong limit is the sample itself: The response rate of 2.85\% (20 interviews by 700 telephone calls) was highly underestimated. Many of the participating companies reported of problems caused by missing or poorly conducted RE, other just had "survived" projects and worked on requirements in this context. Some companies refused an interview and declared that RE is a "nonissue" and they never heard of this. It might be assumed, that in the non-participating companies the awareness of the importance of RE and the RE processes is much lower than in the participating companies.

Another limit regarding the international transferability might be caused by the national situation in Germany with the long tradition in well-trained non-academic staff and long-term employment.

Additionally the focus on business (!) information systems is a - planned - limit of the FaPrAa scope.

\section{Impact on the Quality of Information Systems Projects}

The interviews demonstrated the importance of RE for the success or the failure of information systems projects. But the interviews also show the heterogeneous of the types how RE processes are conducted.

Successful projects have been conducted with different ways in the RE process - if at least the responsible persons had an awareness about the relevance of the requirements.

Less formal processes had been judged as successful by the interviewees

- in companies with low staff fluctuation ...

- and/or stable relationships to externals ... 
- and for tasks with a low innovation grade (regardless if in project organization or line organization).

\section{Impact on the on the Understanding of the RE Process}

The FaPrAa survey has two discriminating differences to the present literature:

- The study does not only focus on how business departments are involved in the RE process but it examines also how business departments are active conducting the RE process.

- Typically, RE literature is focused on project work. This study examines also how the RE process in line management, in non-project work, is conducted.

These results may lead to a more complex, differentiated and at last more realistic view on the RE process and on change management process in (business) organizations. The study underlines the important role of communication in the RE process (see also Davey, B., \& Cope, Chr., 2008).

\section{Further Work}

This study has impact as well for research as for transfer to teaching.

\section{Further Research}

The preliminary results of the FaPrAa study suggest further research in following areas:

- Quantitative evaluation of the results mentioned above.

$\mathrm{RE}$ research often is based on case studies. In the interpretation of grounded theory this is an appropriate method to gather information and to develop hypotheses from the results mentioned above. But to get better knowledge of real world, a quantitative verification of these hypotheses is necessary.

- Which "RE cultures" are successful under which circumstances?

This research question integrates questions of national differences (professional education in different countries, market situations) as well as of different professional cultures, branches and the organization (e.g. SME vs. large enterprises) etc.

- How can the cooperation of system developing companies and their customers be improved?

Which factors influence the cooperation between software companies and their customers? Which grade of domain knowledge is necessary? How can customers anticipate that the new system will fulfill their requirements? Will there be any improvements for the project management, for example by tailoring functional packages?

- $\quad$ RE in line management

Most RE literature is focused on projects. But RE is also an ongoing task for process improvement and information systems maintenance. The results of the FaPrAa study show the importance of business department staff for the RE process in line management.

\section{Transfer to Teaching}

The expected outcome of this project has two directions for transfer:

- Curriculum enlargement in the business studies at the university In the curriculum of business studies at Higher Education Institutes [HEI] the RE subject is not regularly institutionalized. To enable the students to represent their own business 
projects and to collaborate with RE and systems analysis specialists the following content will be useful:

○ awareness of the relevance of well-defined requirements for project success,

O basic introduction in (selected) RE methods,

- project work in which business students conduct the RE process (Weißbach, 2012)

- Development of trainings und learning materials for staff of the business departments

As result of this study, we must accept that RE is performed not only by RE specialists but by different people working in projects and the line organization (see also Fahney et al., 2007). To improve the quality of the process, trainings should be developed for all people working in the RE area of expertise.

\section{Conclusions}

The RE reality is more complex than treated in RE literature. The RE process is in praxis performed by IT departments as well as by business departments. Often line management will define requirements in the improvement process. The interviews illustrate that the success of projects will not depend on who performs the RE tasks, but how the tasks are performed.

Therefore the focus of future work on this topic should be changed from RE as an "interface" between business departments and IT to an "overlap" between business departments and IT.

\section{References}

Capgemini (2012).f IT-Trends 2012. Retrieved November 4, 2012, from http://www.de.capgemini.com/insights/publikationen/it-trends-2012

Cheng, B. H. C., \& Atlee, J. M. (2007). Research directions in requirements engineering. FOSE'07: Future of Software Engineering, Minneapolis

Davey, B., \& Cope, C. (2008). Requirements elicitation - What's missing? Issues in Informing Science and Information Technology, 5, 543-551.

Dörner, C., et al. (2006). End user development in small and medium-sized enterprises: Empirical findings concerning the adaptation process of software systems. In Workshop 'End User Development' at the 'Informatik 2006', Dresden: Springer, 600-603.

Ebert, C. (2012). Systematisches requirements engineering: Anforderungen ermitteln, spezifizieren, analysieren und verwalten. Heidelberg: dpunkt, 4th edition

Engel, C., \& Holm, C. (2007). Projektmanagement Studie 2007, München: Gesellschaft für Projektmanagement

European Community. (2003). Commission recommendation of 6 May 2003 concerning the definition of micro, small and medium-sized enterprises (2003/361/EC). Retrieved November 29, 2012, from http://eur-lex.europa.eu/LexUriServ/LexUriServ.do?uri=OJ:L:2003:124:0036:0041:EN:PDF

Fahney R., \& Herrmann A., \& Weißbach R. (2007). Eine neue dimension, um zwischen requirements engineering und projektmanagement zu unterscheiden (Bericht des Arbeitskreises "RE und PM"). Softwaretechnik-Trends. 27(1), Retrieved November 4, 2012, from http://pi.informatik.unisiegen.de/stt/27_1/01_Fachgruppenberichte/RE/02_SWTTrendsAKBerichtREPM.pdf

Fischer, G. (2009). End-user development and meta-design: Foundations for cultures of participation. In V. Pipek et al. (Eds.), IS-EUD 2009, LNCS 5435, Heidelberg: Springer, 3-14.

Lieberman, H., Paternò, F., Klann, M., \& Wulf, V. (2006). End-user development: An emerging paradigm. In H. Lieberman, F. Paternò, \& V. Wulf, (Eds), End user development (pp. 1-8), Doordrecht: Springer. 
Pipek, V., \& Wulf, V. (2009). Infrastructuring: Towards an integrated perspective on the design and use of information technology. Journal of the Association of Information Systems (JAIS), 10(5), 306-332.

Pohl, K., \& Rupp, C. (2011). Basiswissen requirements engineering - Aus- und Weiterbildung zum 'Certified Professional for Requirements Engineering'. Foundation Level nach IREB-Standard (3rd ed.). Heidelberg: dpunkt.

Robertson, S., \& Robertson, J. (2006). Mastering the requirements process (2nd ed.). Amsterdam: Addison-Wesley.

Standish Group. (2001). Extreme CHAOS.

United Nations. (2008).International standard industrial classification of all economic activities, Rev.4; Retrieved March 16, 2013, from http://unstats.un.org/unsd/cr/registry/regcst.asp?Cl=27

Weißbach, R. (2012). Bridging the communication gap in information system projects. Enabling non-IT professionals for the requirements engineering process. In: Kettunen, Juha et al. (eds.): Applied research and professional education. Proceedings from the first CARPE networking conference in Utrecht on 2-4 November 2011. Turku: Turku UAS 2012, 259-267

Yin, Robert K. (2009). Case study research. Design and methods (4th ed.). Thousand Oaks: Sage.

\section{Biography}

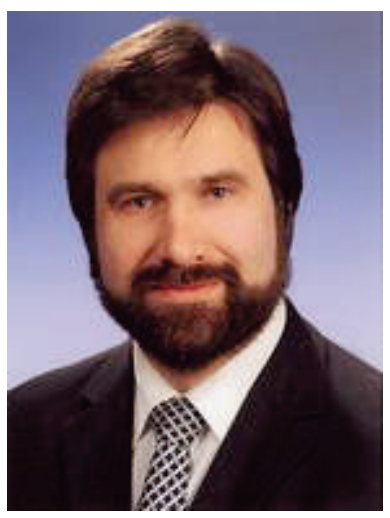

Prof. Dr. Rüdiger Weißbach studied in Berlin, Germany, where he made his M.A. degree in Communication Sciences at Free University Berlin in 1986. From 1987 to 2009 he worked in IT departments in the electrical industry and in financial services. In 2000 he achieved his doctoral degree in Information Sciences at Free University Berlin with a study on technology diffusion and the strategies of ICT implementation. Since 1990 he is teaching students at different universities.

In 2009 Rüdiger Weißbach was appointed to a professorship for Business Informatics at the Business Department of Hamburg University of Applied Sciences. His research topics are Requirements Engineering \& Management, ICT diffusion and adaption and ICT management, especially for SMEs. 